\title{
Detection of Pinholes in Ultrathin Films by Magnetic Coupling
}

\author{
W. F. Egelhoff, Jr., L. Gan, P. J. Chen, C. J. Powell, R. D. McMichael, and R. A. Fry, \\ National Institute of Standards and Technology \\ Gaithersburg, MD 20899 \\ G. Beach, D. Martien, and A. E. Berkowitz \\ Center for Magnetic Recording Research \\ University of California at San Diego \\ La Jolla, CA 92093
}

\begin{abstract}
When two magnetic films are separated by a nonmagnetic film, pinholes in the nonmagnetic film can allow direct contact and, thereby, direct magnetic exchange coupling between the two magnetic films. We have studied this coupling by having one of the magnetic films pinned and leaving the other free to switch at low field. The pinning is accomplished with test structures based on exchange bias and synthetic antiferromagnetic layers. Since the pinning strength increases sharply at low temperatures but orange-peel coupling does not, lowtemperature $(77 \mathrm{~K})$ measurements appear to identify whether an observed coupling arises primarily from magnetic coupling through pinholes or primarily from orange-peel roughness. Our measurements appear to indicate that the observed coupling arises primarily from magnetic coupling through pinholes for $\mathrm{Cu}$ films less than $2.1 \mathrm{~nm}$ thick and for $\mathrm{Al}_{2} \mathrm{O}_{3}$ films less than 0.6 $\mathrm{nm}$ thick but primarily from roughness-induced (orange-peel) magnetostatic coupling for larger thicknesses.
\end{abstract}

\section{Introduction}

Pinholes are widely believed to play a key role in limiting the performance of both giant magnetoresistance (GMR) spin valves and magnetic tunnel junctions (MTJs). ${ }^{1}$ It is generally believed that as the spacer layer, $\mathrm{Cu}$ in the case of spin valves and $\mathrm{Al}_{2} \mathrm{O}_{3}$ in the case of MTJs, is made thinner the value of the magnetoresistance (MR) increases until pinholes occur. Pinholes couple the two magnetic layers ferromagnetically, making it difficult to achieve antiparallel alignment, and thereby limiting the MR.

Pinholes are not easy to observe. There is some evidence from transmission electron microscopy (TEM) for the existence of pinholes, but in systems such as $\mathrm{Co} / \mathrm{Cu} / \mathrm{Co}$ the low electron-scattering contrast between elements of similar atomic number makes conclusive identification of pinholes difficult. ${ }^{1}$ Another problem is that the thickness of the Cu layer is typically much smaller $(\approx 2 \mathrm{~nm})$ than the depth of the TEM sample in the beam direction $(\approx 20$ $\mathrm{nm})$. If the diameter of a pinhole in the $\mathrm{Cu}$ film is similar to the thickness of the $\mathrm{Cu}$ film, it would be only $\approx 10 \%$ of the sample depth thus exacerbating the contrast problem. In systems such as $\mathrm{Al}_{2} \mathrm{O}_{3} / \mathrm{Co}$, there is some evidence that electrochemical deposition of $\mathrm{Cu}$ clusters can identify 
pinholes, although the applied potential may also create pinholes . ${ }^{1}$

Two groups have recently reported the use of magnetic hysteresis loops to study coupling between magnetic films of different coercivity separated by an insulating film. ${ }^{2}$ The method appears to have much promise, and the present work is an extension of this concept.

The present work has two aims. One is to develop an improved method for observing the onset of pinholes as the spacer layer is made thinner. The other is to develop an improved method for distinguishing the regime of spacer-layer thickness in which pinhole coupling dominates from the one in which orange-peel coupling dominates.

\section{Experimental}

The $\mathrm{NiO}$ substrates used in this work were polycrystalline films $\approx 50 \mathrm{~nm}$ thick, deposited on 4" Si wafers by reactive magnetron sputtering at the University of California at San Diego. At the National Institute of Standards and Technology (NIST), the wafers were cleaved into $\approx 1$ $\mathrm{cm}^{2}$ squares, cleaned ultrasonically in a detergent solution, rinsed in distilled water, blown dry, and installed in the deposition chamber. After bakeout, the deposition chamber has a base pressure of $3 \times 10^{-8} \mathrm{~Pa}\left(2 \times 10^{-10}\right.$ Torr), of which $90 \%$ is $\mathrm{H}_{2}$. The metal films were deposited at room temperature by dc-magnetron sputtering in $0.3 \mathrm{~Pa}$ ( 2 mTorr) Ar at a typical rate of $\approx 0.05$ $\mathrm{nm} / \mathrm{s}$. Oxide fims are deposited by reactive sputtering, adding $0.01 \mathrm{~Pa}\left(10^{-4}\right.$ Torr $) \mathrm{O}_{2}$ to the Ar.

Magnetoresistance (MR) measurements were made at NIST with a 4-point probe in a direct current mode. The values of the coupling reported have an estimated uncertainty of $\pm 5 \%$ due to the slight skew in the hysteresis loop of the free Co layer. The calibration of the Hall probe used for measurement of the applied field during MR measurements has an uncertainty of $\pm 2 \%$. The measurements at $77 \mathrm{~K}$ were performed with the sample immersed in liquid nitrogen. Additional experimental details may be found in Ref. 3.

\section{Results and Discussion}

Structures of the type illustrated in Fig. 1 were used to investigate the magnetic coupling between two ferromagnetic layers. The concept behind the structure in Fig. 1 is to have two Co films separated by a non-magnetic spacer layer. The upper Co film is magnetically pinned by the synthetic antiferromagnet $\mathrm{Co} / \mathrm{Ru} / \mathrm{Co}$ and the natural antiferromagnet $\operatorname{Ir}_{20} \mathrm{Mn}_{80}$. The Co film below the non-magnetic spacer layer is free switch at low field whenever the non-magnetic spacer layer is thick enough to prevent magnetic coupling.

The lower parts of the structure constitute a GMR spin valve. GMR measurements are used to observe the hysteresis loop of the free Co layer. The synthetic antiferromagnet $\mathrm{Co} / \mathrm{Ru} / \mathrm{Co}$ and the natural antiferromagnet $\mathrm{NiO}$ substrate serve to pin the Co layer that is under the $\mathrm{Cu}$. The $\mathrm{Cu}$ layer thickness in the spin valve is chosen to be $4 \mathrm{~nm}$ to ensure that the contribution to the coupling is insignificant from the Co layer below the $\mathrm{Cu}$.

The coupling is observed as a shift from zero field in the center of the GMR hysteresis loop of the "free" Co. Figure 2 presents the coupling data for $\mathrm{Al}_{2} \mathrm{O}_{3}$ as the non-magnetic spacer layer. With no spacer layer, the two Co films form a single layer $5 \mathrm{~nm}$ thick and the hysteresis loop center is shifted $\approx 30 \mathrm{mT}$ ( $300 \mathrm{Oe}$ ) from zero field. At $77 \mathrm{~K}$ this shift increases to $\approx 60 \mathrm{mT}$ $(600 \mathrm{Oe})$ as the synthetic antiferromagnet $\mathrm{Co} / \mathrm{Ru} / \mathrm{Co}$ becomes stronger. 


\begin{tabular}{|c|}
\hline $10 \mathrm{~nm} \mathrm{IrMn}$ \\
\hline $2.5 \mathrm{~nm} \mathrm{Co}$ \\
\hline $0.5 \mathrm{~nm} \mathrm{Ru}$ \\
\hline $2.5 \mathrm{~nm} \mathrm{Co}$ \\
\hline Non-magnetic spacer layer \\
\hline Free $2.5 \mathrm{~nm} \mathrm{Co}$ layer \\
\hline $4 \mathrm{~nm} \mathrm{Cu}$ \\
\hline $2.5 \mathrm{~nm} \mathrm{Co}$ \\
\hline $0.5 \mathrm{~nm} \mathrm{Ru}$ \\
\hline $2.5 \mathrm{~nm} \mathrm{Co}$ \\
\hline NiO substrate \\
\hline
\end{tabular}

Figure 1. An illustration of the type of test structure used in this study.

In Fig. 2 a spacer layer of $0.6 \mathrm{~nm} \mathrm{Al}_{2} \mathrm{O}_{3}$ is sufficient to suppress any significant temperature dependence in the coupling field. Apparently, this is the thickness at which magnetic pinholes cease to be significant. The coupling that is observed for $0.6 \mathrm{~nm}$ or more of $\mathrm{Al}_{2} \mathrm{O}_{3}$ is probably magnetostatic and comes from the orange-peel effect. ${ }^{4}$ Only a very slight increase in orange-peel coupling would be expected since the magnetization of Co increases by less than $1 \%$ from $295 \mathrm{~K}$ to $77 \mathrm{~K}$.

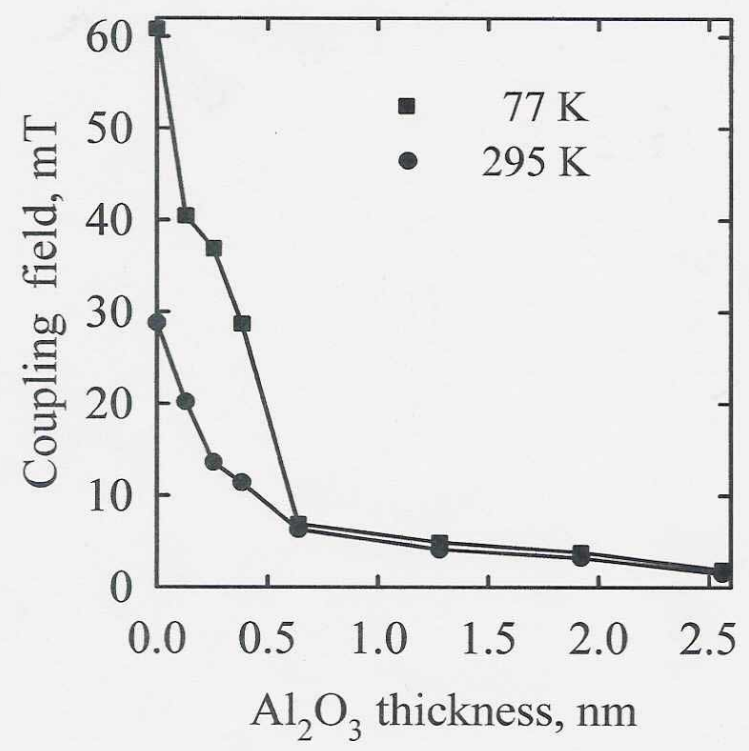

Figure 2. The coupling field observed in the GMR hysteresis loop of the free Co layer when the non-magnetic spacer layer is $\mathrm{Al}_{2} \mathrm{O}_{3}$, as a function of the spacer layer thickness. 
It is significant that the magnetic pinholes appear to close up at an $\mathrm{Al}_{2} \mathrm{O}_{3}$ thickness of 0.6 $\mathrm{nm}$. In studies of magnetic tunnel junctions, it is generally found that this is the practical limit on how thin the $\mathrm{Al}_{2} \mathrm{O}_{3}$ barrier can be made. Thinner $\mathrm{Al}_{2} \mathrm{O}_{3}$ layers yield drastic reductions in tunneling MR. The results of Fig. 2 suggest that, in this thickness regime, magnetic pinholes would make it difficult to achieve the antiparallel magnetic state. Moreover, if as seems likely, the magnetic pinholes represent direct Co-Co contacts, these pinholes may be expected to act as current short circuits as well.

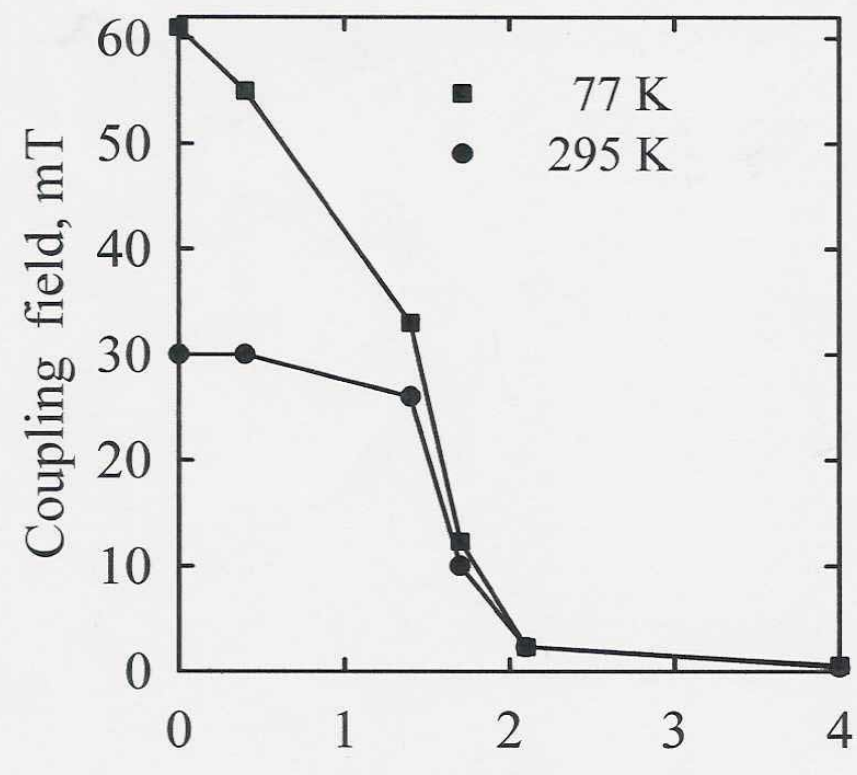

$\mathrm{Cu}$ thickness, nm

Figure 3. The coupling field observed in the GMR hysteresis loop of the free Co layer when the non-magnetic spacer layer is $\mathrm{Cu}$, as a function of the spacer layer thickness.

Figure 3 presents the coupling results for $\mathrm{Cu}$ as the non-magnetic spacer layer. It may be noted that this choice of spacer layer turns the structure into a dual spin valve. As a result, there will be a contribution to the GMR from the top half of the dual spin valve. However, this effect does not detract from the validity of the measured coupling. The bottom $\mathrm{Cu}$ film is fixed at a thickness of $4 \mathrm{~nm}$ to make any contribution to the coupling from that side negligible. Only the upper $\mathrm{Cu}$ layer thickness is varied, and its thickness alone is responsible for the observed coupling.

The temperature dependence observed in Fig. 3 suggests that the magnetic pinholes dominate the coupling for $\mathrm{Cu}$ thicknesses from $0 \mathrm{~nm}$ to $\approx 1.5 \mathrm{~nm}$ and become insignificant when the $\mathrm{Cu}$ is thicker than $\approx 2 \mathrm{~nm}$. Not surprisingly, this thickness corresponds well with what is generally used in GMR spin valves. It is commonly observed in GMR spin valves that below about $2 \mathrm{~nm}$ the coupling rises steeply. ${ }^{6}$ 


\section{Conclusions}

The temperature dependence of the magnetic coupling is found to be a useful approach to separating the effects of magnetic pinholes in non-magnetic spacer layers from the effects of magnetostatic coupling, such as the orange-peel effect. Test structures based on GMR spin valves are convenient for investigations of such phenomena. We find that for $\mathrm{Cu}$ films of $\approx 2 \mathrm{~nm}$ or more and for $\mathrm{Al}_{2} \mathrm{O}_{3}$ films of $\approx 0.6 \mathrm{~nm}$ or more magnetic pinholes do not make a significant contribution to the coupling.

\section{References}

1. J. F. Bobo, M. Piecuch, E. Snoeck, J. Magn. Magn. Mater. 126, 440 (1993); S. K. J. Lenczowski, C. Schonenberger, M. A. M. Gijs, and W. J. M. DeJonge, J. Magn. Magn. Mater. 148, 455 (1995); M. T. Kief, J. Bresowa, and Q. Leng, J. Appl. Phys. 79, 4766 (1996); H. Kikuchi, J. F. Bobo, and R. L. White, IEEE Trans. Mag. 33, 3583 (1997); F. Stobiecki, T. Lucinski, R. Gontarz, M. Urbaniak, Mater. Sci. For. 287, 513 (1998); J. F. Bobo, H. Kikuchi, O. Redon, E. Snoeck, M. Piecuch, R. L. White, Phys. Rev. B 60, 4131 (1999 ); T. Cohen, J. Yahalom, W. D. Kaplan, Rev. Anal. Chem. 18, 279 (1999).; D. Allen, R. Schad, G. Zangari, I. Zana, D. Yang, M. C. Tondra, and D. Wang, J. Vac. Sci. Technol. A 18, 1830 (2000); D. Allen, R. Schad, G. Zangari, I. Zana, D. Yang, M. C. Tondra, and D. Wang, J. Appl. Phys. 87, 5188 (2000); B. J. Jönsson-Åkerman, R. Escudero, C. Leighton, S. Kim, I. K. Schuller, and D. A. Rabson, Appl. Phys. Lett. 77, 1870 (2000); B. Szymanski and F. Stobiecki, Acta Phys. Pol. A 97, 535 (2000); D. Allen, R. Schad, G. Zangari, I. Zana, D. Yang, M. C. Tondra, and D. Wang, Appl. Phys. Lett. 76, 607 (2000); M. F. Gillies and A. E. T. Kuiper, J. Appl. Phys. 88, 5894 (2000); H. Boeve, J. De Boeck, and G. Borghs, J. Appl. Phys. 89, 482 (2001); D. X. Yang, B. Shashishekar, H. D. Chopra, P. J. Chen and W. F. Egelhoff, J. Appl. Phys., submitted. 2. C. L. Platt , M. R. McCartney, F. T. Parker, and A. E. Berkowitz, Phys. Rev. B 61, 9633 (2000); T. Luciński, S. Czerkas, H. Brückl, and G. Reiss, J. Mag. Mat. Mat. 222, 327 (2000). 3. W. F. Egelhoff, Jr., T. Ha, R.D.K. Misra, Y. Kadmon, J. Nir, C. J. Powell, M. D. Stiles, R. D. McMichael, C.-L. Lin, J. M. Sivertsen, J. H. Judy, K. Takano, A. E. Berkowitz, T. C. Anthony, and J. A. Brug, J. Appl. Phys., 78, 273 (1995);W. F. Egelhoff, Jr., P. J. Chen, C. J. Powell, M. D. Stiles, R. D. McMichael, C.-L. Lin, J. M. Sivertsen, J. H. Judy, K. Takano and A. E. Berkowitz, J. Appl. Phys. 80, 5183 (1996); W. F. Egelhoff, Jr., P. J. Chen, C. J. Powell, M. D. Stiles, R. D. McMichael, J. H. Judy, K. Takano, and A. E. Berkowitz, J. Appl. Phys., 82, 6142 (1997)

4. J. C. S. Kools, W. Kula, D. Mauri, T. Lin, J. Appl. Phys. 85, 4466 (1999); B. D. Schrag, A. Anguelouch, S. Ingvarsson, G. Xiao, Y. Lu, P. L. Trouilloud, A. Gupta, R. A. Wagner, W. J. Gallagher, P. M. Rice, and S. S. P. Parkin, Appl. Phys. Lett. 77, 2373 (2000).

5. J. S. Moodera, T. H. Kim, C. Tanaka, and C. H. de Groot, Phil. Mag. B 80, 195 (2000).

6. W. F. Egelhoff, Jr., P. J. Chen, C. J. Powell, M. D. Stiles, R. D. McMichael, J. H. Judy, K. Takano, and A. E. Berkowitz, J. Appl. Phys., 82, 6142 (1997) 